\title{
MATERNAL AND FOETAL EFFECTS OF METHOXYFLURANE ANAESTHESIA IN THE PREGNANT EWE
}

\author{
J. Bruce Smith, F.A. Manning, and R.J. Palahniuk
}

Methoxyflurane is widely used as an analgesic during the first and second stages of labour. Low inspired concentrations provide excellent maternal pain relief without causing foetal or neonatal depression. ${ }^{1-5}$ More recently, the addition of methoxyflurane in higher concentrations to standard Caesarean section anaesthetic techniques has been advocated. ${ }^{6-8}$ This allows improved oxygenation of the mother and foetus while protecting against maternal awareness. ${ }^{9-12}$ These advantages at Caesarean section, however, might be outweighed by the possible adverse effects of anaesthetic concentrations of methoxyflurane on the maternal and foetal cardiovascular systems. Since this had never been systematically studied, the present study was designed to determine the effects of three levels of methoxyflurane anaesthesia on the cardiovascular function, acid-base status and oxygenation of both the mother and foetus in a pregnant ewe preparation.

\section{METHOD}

Nine pregnant ewes carrying a single foetus were studied. All animals were within three weeks of term (19-21 weeks gestation). Using halothane-oxygen anaesthesia, polyvinyl catheters were placed in both maternal femoral arteries, one femoral vein, and in the right atrium through the jugular vein. A midline abdominal incision was made and the uterus was exposed. Through a small hysterotomy, a polyvinyl catheter was inserted in one foetal femoral artery. A precalibrated Statham electromagnetic flow probe was secured on a main uterine artery. The animals were allowed to recover from anaesthesia and surgery for at least 24 hours before any experiment was performed. A diagram of the experimental preparation is shown in Figure 1.

On the day of a study the ewe was placed on her side awake, and 100 per cent oxygen was administered by mask for a 60 -minute control period. Following the control period, anaesthesia was induced with methoxyflurane in oxygen and the trachea was intubated. Ventilation was controlled using an Ohio 200 ventilator to maintain approximately the same maternal $\mathrm{Pa}_{\mathrm{CO}_{2}}$ as during the control period. End-tidal methoxyflurane concentration was measured with a Beckman IR 215 infrared gas analyser, and was held constant at $1.0,1.5$ or $2.0 \mathrm{MAC}$ for $90 \mathrm{~min}$ -

From the Departments of Anaesthesia and Obstetrics and Gynaecology, Health Sciences Centre and the University of Manitoba, Winnipeg, Manitoba.

This study was supported by the Medical Research Council of Canada. Presented in part at the Canadian Anaesthetists' Society Meeting, St. John's, Newfoundland, June, 1974.

Address reprint requests to: Dr. R. Palahniuk, Department of Anaesthesia, Health Sciences Centre, Winnipeg, Manitoba, Canada. 


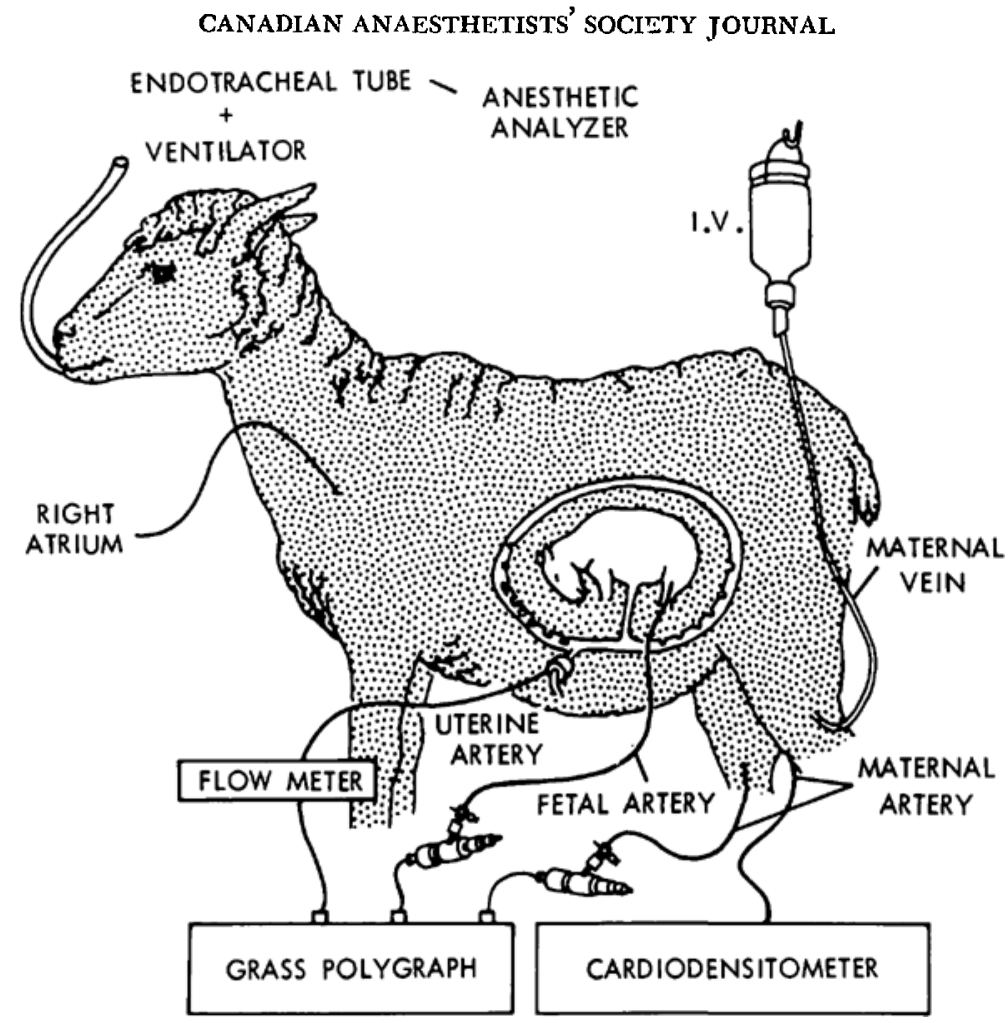

Figure 1. Sheep experimental preparation. See text for explanation.

utes. Methoxyflurane MAC was previously determined to be 0.18 per cent in term pregnant sheep. ${ }^{15}$

Maternal and foetal blood pressures and heart rates were measured continuously using Statham strain gauges connected to a Grass polygraph recorder. Mean uterine blood flow was measured continuously using a Statham SP2202 Blood Flowmeter. Maternal cardiac output was measured in duplicate by dye dilution, using a Waters XC302 densitometer and Waters DCR-701 cardiac output computer with cardiogreen dye as the indicator.

Uterine vascular conductance was calculated, employing the formula: uterine vascular conductance $(\mathrm{ml} / \mathrm{min} /$ torr $)=$

$$
\frac{\text { mean uterine blood flow }(\mathrm{ml} / \mathrm{min})}{\text { mean maternal arterial blood pressure (torr) }}
$$

Body temperature was measured continuously with a Yellow Springs rectal probe. Maternal and foetal $\mathrm{Pa}_{\mathrm{O}_{3}}, \mathrm{~Pa}_{\mathrm{CO}_{2}}$ and $\mathrm{pH}$ were measured at $37^{\circ} \mathrm{C}$. immediately after sampling, using a Radiometer BMS3 Blood Micro System and a Radiometer $\mathrm{C}_{4} \mathrm{M} 72$ digital acid-base analyser. All values were corrected to body temperature. $\mathrm{pH}$ measurements were converted to hydrogen ion concentrations in order to facilitate statistical analysis. Base excess values were calculated using the Severinghaus slide rule, ${ }^{13}$ and foetal oxygen saturation was calculated using the nomogram of Hellegers. ${ }^{14}$ 
Control values for all the variables are the means of determinations taken at 15-minute intervals during the control period, while during the study period, maternal and foetal blood pressures, heart rates and uterine blood flow were measured continuously, and maternal cardiac output and maternal and foetal arterial blood gases and acid-base variables were measured at 15, 30, 60, and 90 minutes after reaching the desired end-tidal methoxyflurane concentration.

Only one concentration of methoxyflurane was administered on any one day and the administrations were randomized. Three animals were studied at 1.0 $\mathrm{MAC}$, five at 1.5 MAC and five at 2.0 MAC.

A student's t-test for paired data was used to compare changes from control within any group of animals. $\mathrm{P}<0.05$ was considered significant.

\section{ResulTs}

Maternal and foetal cardiovascular data, arterial hydrogen ion concentrations and foetal oxygen saturation during the experimental period are expressed as per cent change from control. Maternal and foetal $\mathrm{Pa}_{\mathrm{CO}_{2}}, \mathrm{~Pa}_{\mathrm{O}_{2}}$, and base excess are expressed as absolute values (Tables I-III).

\subsection{MAC (Table I)}

There were no consistent changes from the control period in any of the variables, although maternal blood pressure, cardiac output and uterine blood flow tended to decrease slightly while uterine vascular conductance remained unchanged or decreased.

\subsection{MAC (T'able II - Figures 2-6)}

Maternal blood pressure and cardiac output decreased moderately. Uterine blood flow decreased significantly at 15,30 and 90 minutes, and while uterine vascular conductance tended to increase, the changes were not statistically significant.

Foetal blood pressure decreased slightly while maternal and foetal heart rates were unchanged.

Maternal acid-base variables, $\mathrm{Pa}_{\mathrm{CO}_{2}}$ and $\mathrm{Pa}_{\mathrm{O}_{2}}$ did not change from control. Mild foetal respiratory acidosis developed as indicated by the slight increase in foetal $\mathrm{Pa}_{\mathrm{CO}}$, and foetal hydrogen ion concentration. Foetal base excess was unchanged from control. Foetal oxygen saturation tended to decrease but was significantly depressed only at the 30 -minute period.

\subsection{MAC (Table III - Figures 2-6)}

2.0 MAC methoxyflurane caused marked decreases in maternal blood pressure and cardiac output. Uterine blood flow was severely depressed at the 15- and 30minute intervals but tended to improve by 60 and 90 minutes. Uterine vascular conductance was not significantly changed from control but tended to increase slightly. Maternal acid-base variables, $\mathrm{Pa}_{\mathrm{OO}_{2}}$ and $\mathrm{Pa}_{\mathrm{O}_{2}}$ were unchanged.

Marked increases in foetal hydrogen ion concentration occurred as a result of increased foetal $\mathrm{PaCO}_{2}$ and significant falls in foetal base excess. Foetal oxygen saturation was decreased. 


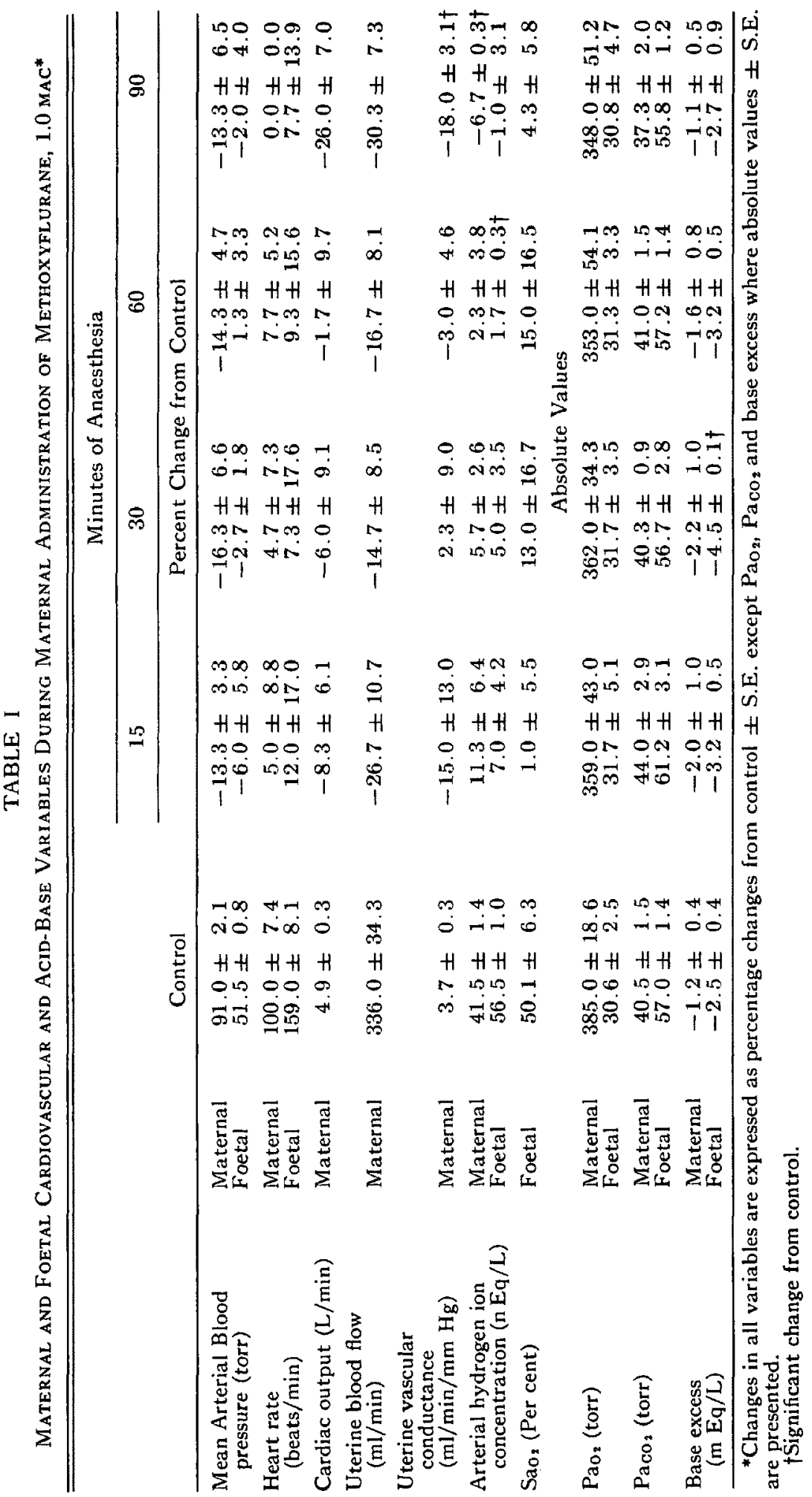




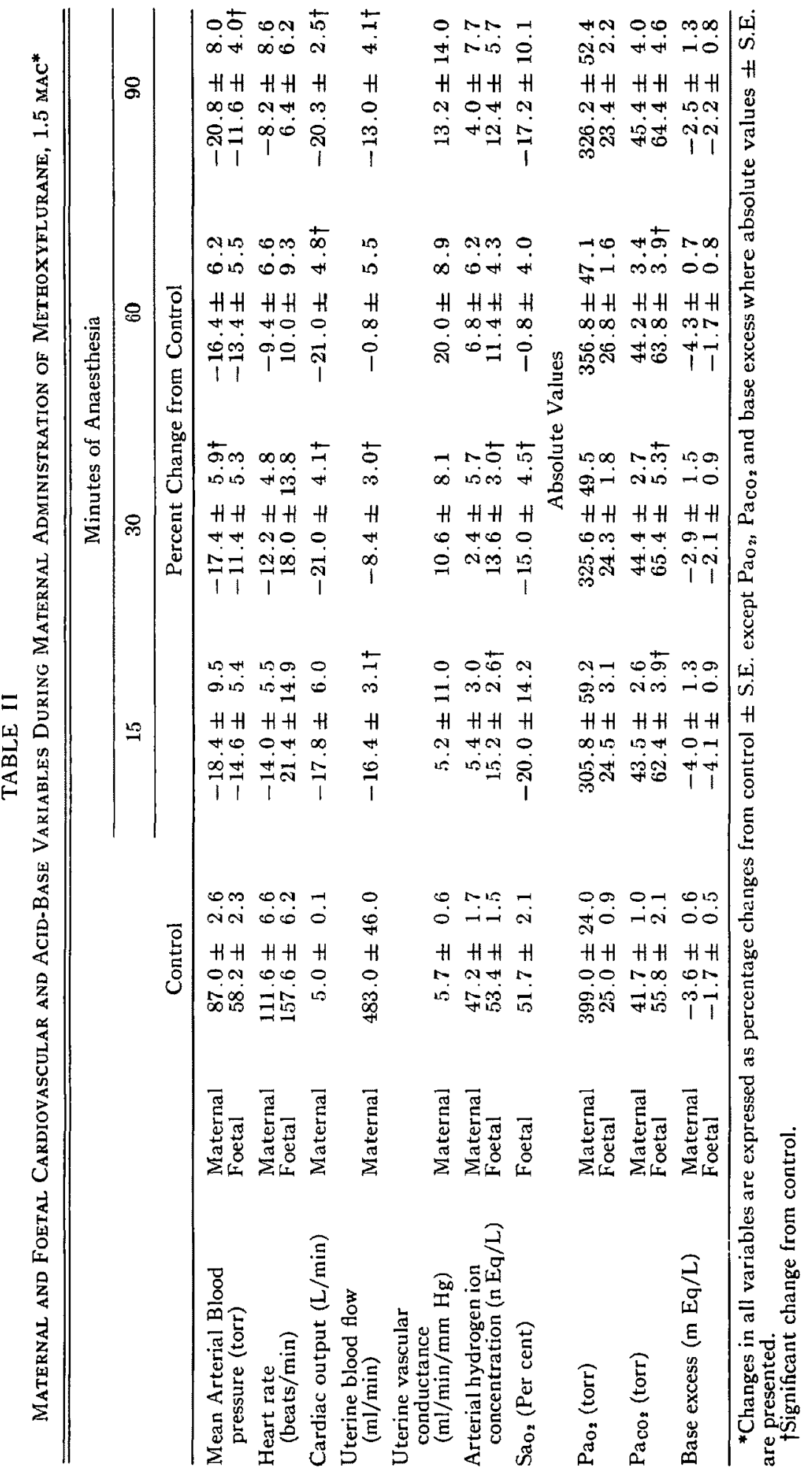




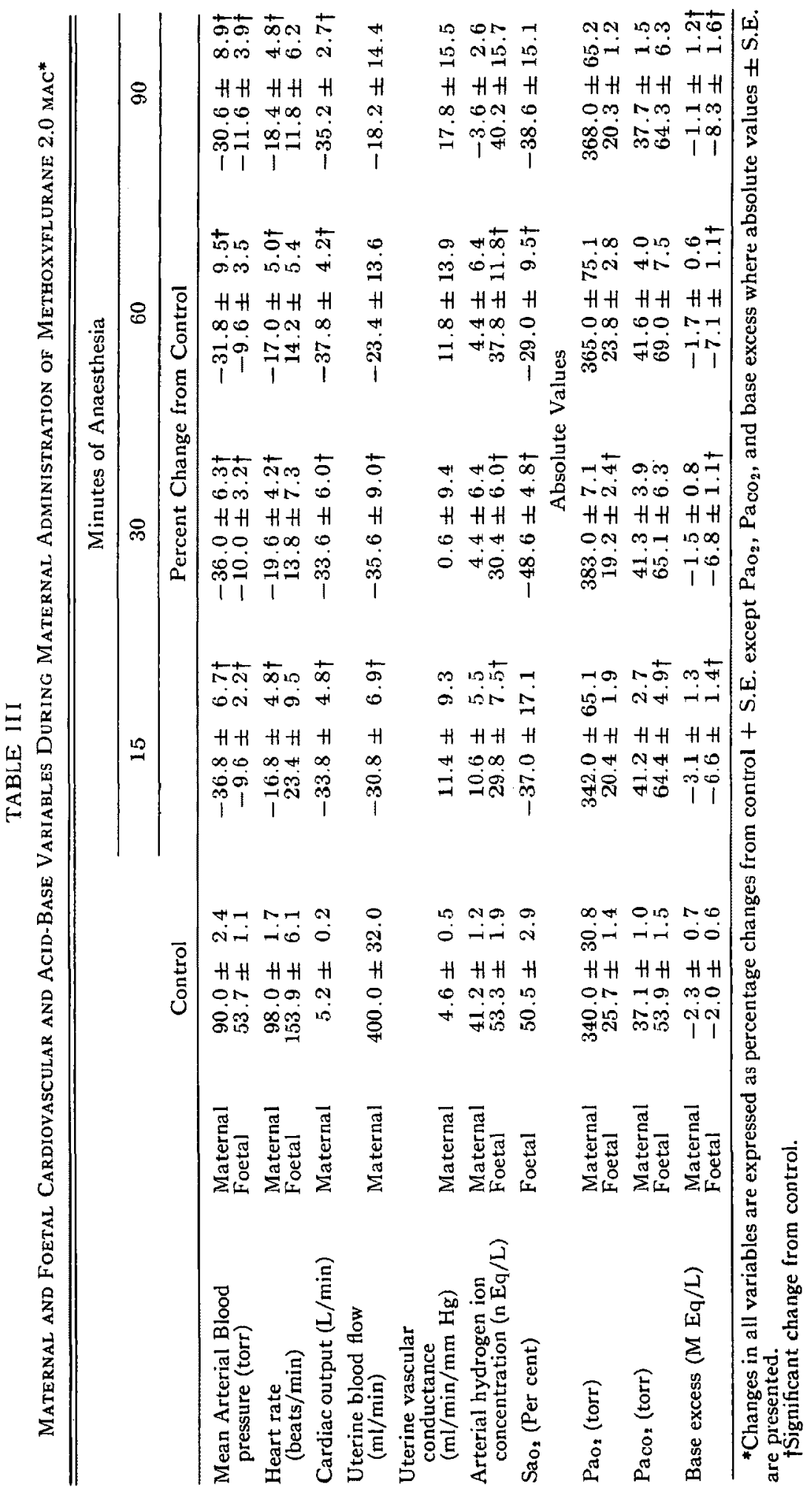




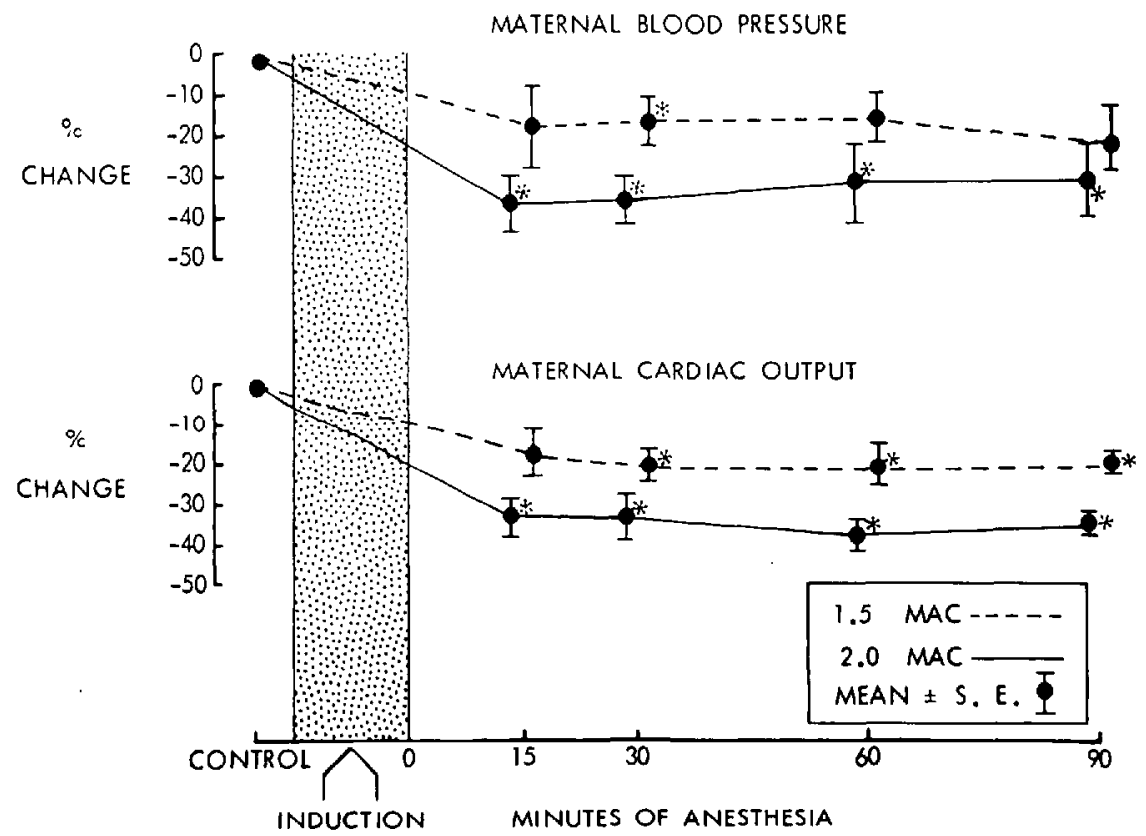

FIgURE 2. Changes from control values in mean maternal arterial blood pressure and cardiac output during 1.5 and 2.0 MAC methoxyflurane anaesthesia.

= significant change from control.
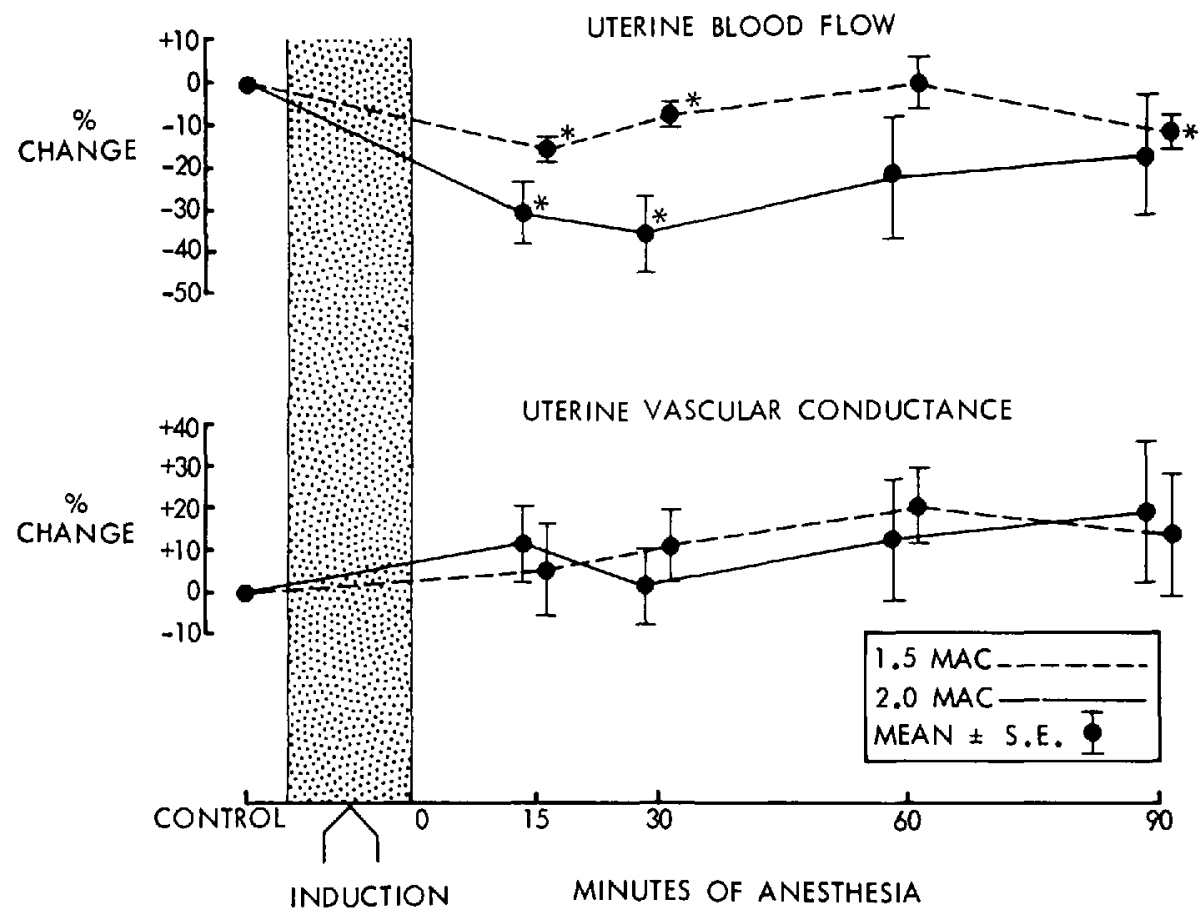

FIgUre 3. Changes from control values in uterine blood flow and vascular conductance during 1.5 and $2.0 \mathrm{MAC}$ methoxyflurane anaesthesia.

= significant change from control. 


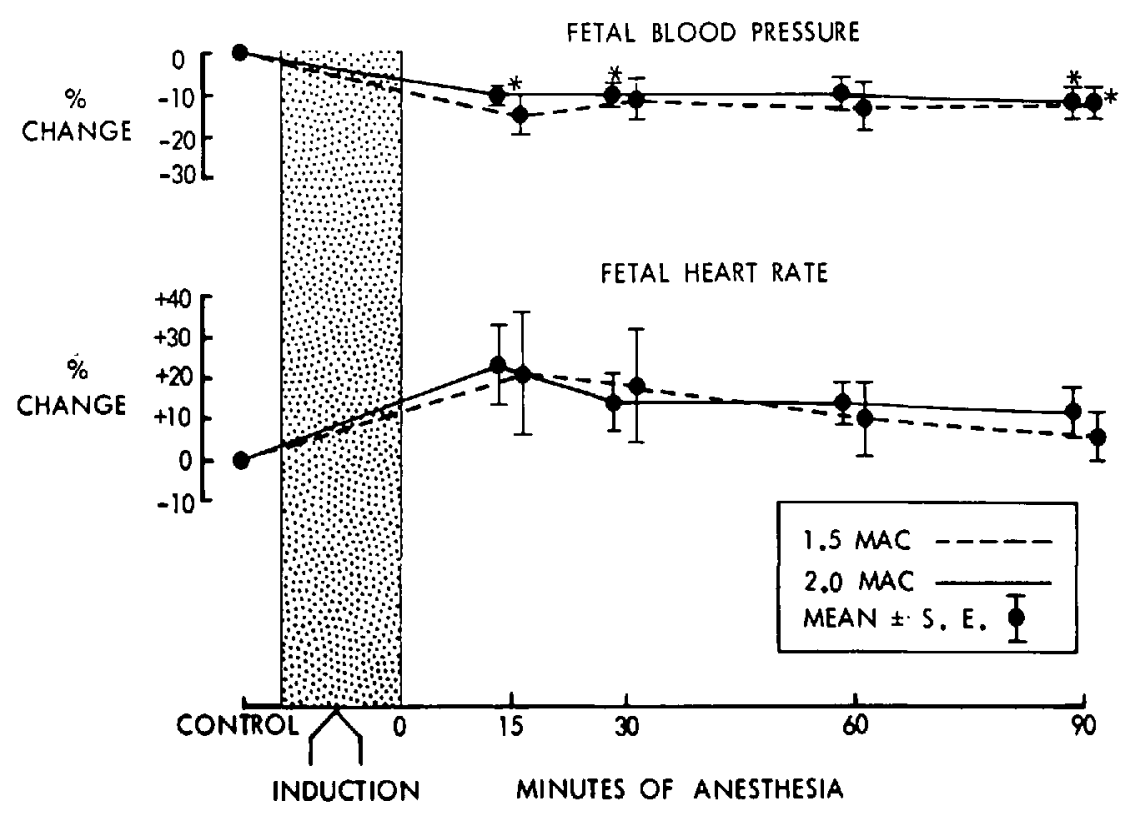

Figure 4. Changes from control values in mean foetal arterial blood pressure and heart rate during 1.5 and $2.0 \mathrm{MAC}$ methoxylurane anaesthesia.

" = significant change from control.

\section{Discussion}

Matemal blood pressure and cardiac output became progressively more depressed as deeper levels of methoxyflurane anaesthesia were employed. While uterine blood flow was markedly reduced only at $2.0 \mathrm{MAC}$ anaesthesia, some depression was also seen at 1.0 and 1.5 MAC. The fall in uterine blood flow at 1.0 MAC was unexpected, especially when maternal blood pressure and cardiac output were only minimally depressed. As there were only three animals in this group and the results were quite variable, the changes in uterine blood flow were not statistically significant. The absence of a corresponding foetal acidosis and hypoxaemia suggests the change observed in uterine blood flow was also not physiologically significant.

Uterine vascular conductance indicates any tendency towards vasodilatation or constriction in the uterine vascular bed. In previous studies of the effects of anaesthetics on uterine blood flow, ${ }^{16}$ we found that halothane and isoflurane tended to cause uterine vasodilatation at light and deep levels of anaesthesia. It is interesting that a similar response in the uterine vasculature is not seen with methoxyflurane.

Maternal blood gases and hydrogen ion concentration were not changed by any level of methoxyflurane anaesthesia.

Foetal blood pressure was mildly reduced by methoxyflurane, while the foetal heart rate tended to increase. Foetal hydrogen ion concentration tended to increase with deepening levels of anaesthesia, and this acidosis was both respira- 
FETAL HYDROGEN ION CONCENTRATION

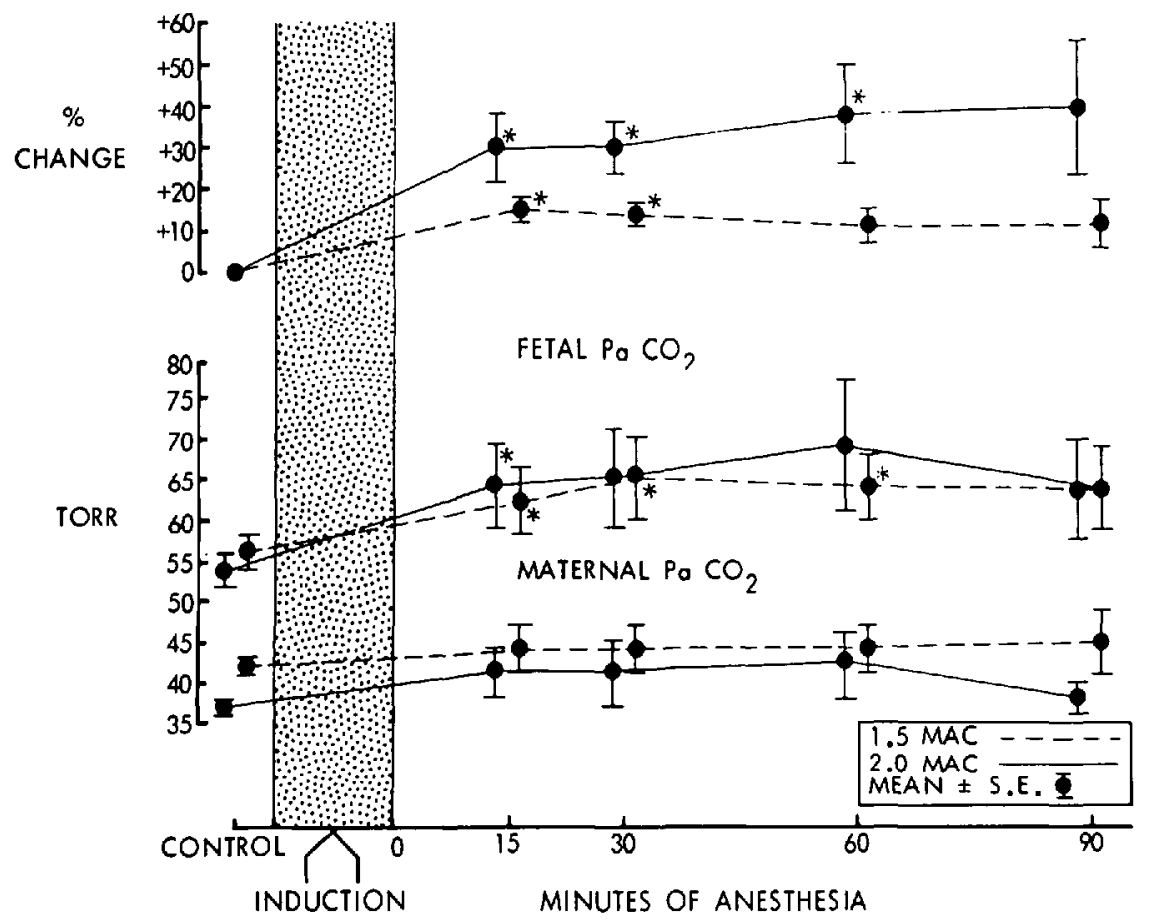

Figure 5. Changes from control values in foetal hydrogen ion concentration and maternal and foetal $\mathrm{Pa}_{\mathrm{OO}_{2}}$ during 1.5 and $2.0 \mathrm{MAC}$ methoxyflurane anaesthesia.

* = significant change from control.

FETAL BASE EXCESS

$M . E Q$. PER L.
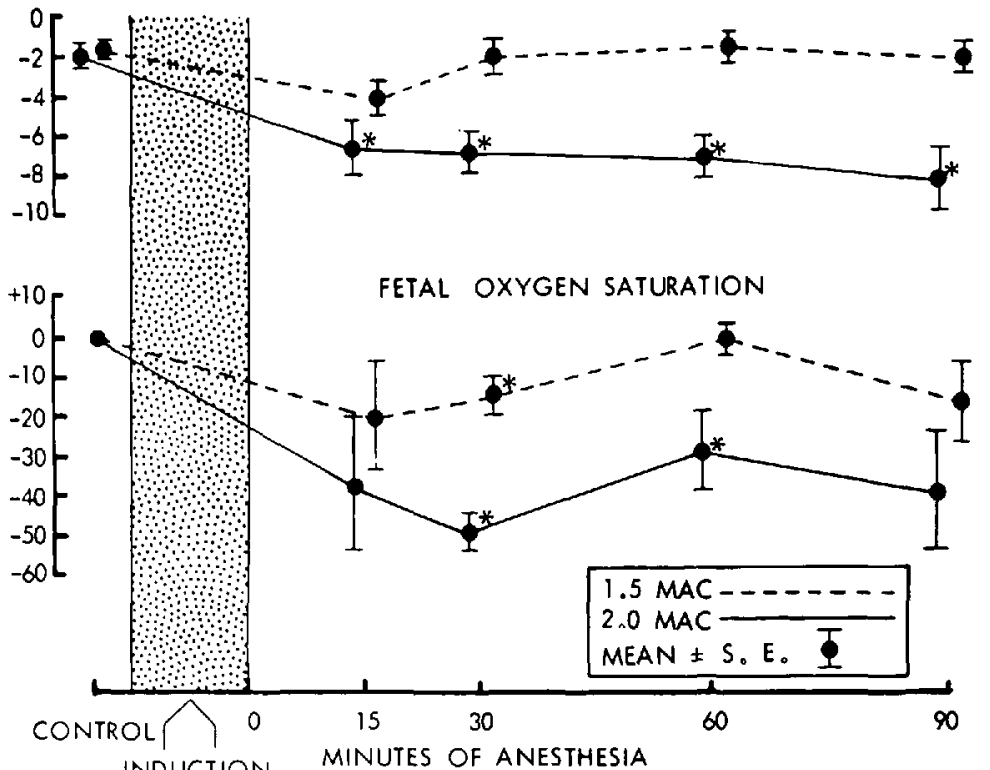

Figure 6. Changes from control values in foetal base excess and foetal oxygen saturation during 1.5 and 2.0 MAC methoxyflurane anaesthesia.

" = significant change from control. 
tory (increased $\mathrm{Pa}_{\mathrm{CO}_{2}}$ ) and metabolic (reduced base excess) in nature. The most marked changes in the foetal acid-base status were seen at 2.0 MAC anaesthesia when the uterine blood flow was most depressed. Corresponding foetal hypoxaemia developed at 2.0 MAC.

Presuming the applicability of these studies to man, light levels of methoxyflurane used for obstetrical anaesthesia or operations during pregnancy would seem to have no deleterious effects on maternal or foetal uteroplacental perfusion and foetal blood gases, while deeper levels can certainly reduce utero-placental perfusion and adversely affect the foetus.

It must be remembered, however, that although acidosis and hypoxaemia are the extreme result of anaesthetic-related maternal cardiovascular depression, neonatal depression might also be expected as a result of CNS depression caused by methoxyflurane, even in the absence of decreased utero-placental perfusion. No attempt was made to investigate the extent of narcotization of the lambs in this study.

\section{SUMMARY}

Maternal and foetal cardiovascular, blood gas and acid-base changes were studied during 90 minutes of methoxyflurane anaesthesia. At 1.0 and 1.5 MAC anaesthesia, despite slight to moderate falls in maternal blood pressure, cardiac output and uterine blood flow, no serious foetal deterioration was seen. 2.0 MAC methoxyflurane was associated with marked falls in maternal blood pressure, cardiac output and uterine blood flow. Foetal hypoxaemia and a mixed respiratory and metabolic acidosis developed. Little foetal cardiovascular depression was seen with any level of anaesthesia. There was no direct effect of methoxyflurane on the uterine vasculature.

\section{RÉSUMÉ}

Cette étude a porté sur les changements cardiovasculaires et acidobasiques survenant chez les brebis enceintes et leur foetus durant 90 min d'anesthésie au méthoxyflurane. A une profondeur d'anesthésie correspondant à 1.0 et $1.5 \mathrm{MAC}$, on n'a observé aucune détérioration de l'état du foetus malgré une chute de pression modérée chez la mère ainsi qu'une diminution de son débit cardiaque et du flat utérin.

A une profondeur équivalent à $2 \mathrm{MAC}$, on observe une chute de la pression artérielle accentuée de même qu'une diminution du débit cardiaque et du débit utérin, au point d'entrainer une hypoxémie foetale avec acidose respiratoire et métabolique épargnant cependant le système cardiovasculaire qui est peu touché. Aucun effet direct du méthoxyflurane sur la circulation utérine n’a pu être observé.

\section{ACKNOWLEDGMENTS}

Ms. Maureen Cumming and Mr. Wayne Pucci provided able technical assistance, and Mrs. Darlene Evaniuk provided secretarial skills. 


\section{REFERENCES}

1. Palahniuk, R. Inhalation anesthesia and analgesia in obstetrics, in The Anesthesiologist, Mother and Newborn. S.M. Shnider \& F. Moya, Eds. Williams \& Wilkins Co., Baltimore, pp. 56-63 (1974).

2. Shnmer, S.M., Steffenson, J.L., \& Margolis, A. Methoxyflurane analgesia in obstetrics. Obstet. Gynec. 33: 594 (1969).

3. LatTo, I.P., Rosen, M., \& Molloy, M.J. Absence of accumulation of methoxyflurane during intermittent self-administration for pain relief in labor. Br. J. Anaesth. 44: 39 (1972).

4. Clarke, R.B., Cooper, J.O., Brown, W.E., \& Greifenstein, F.E. An evaluation of methoxyflurane analgesia and anesthesia for obstetrics. Southern Med. J. 61: 687 (1968).

5. SMitr, B.E. \& MovA, F. Inhalation analgesia with methoxyflurane for vaginal delivery. Southem Med. J. 61: 386 (1968).

6. Ivankovic, A.D., Elam, J.O., \& Huffman, J. Methoxyflurane anesthesia for Caesarean section. J. Reprod. Med. 6: 105 (1971).

7. Houle, G.L. \& Gerter, M. Methoxyflurane: clinical and laboratory studies during Caesarean section. Anesth. Analg. (Cleveland) 48: 1011 (1969).

8. LatTo, I.P. \& Wainwricht, A.C. Anaesthesia for Caesarean section. Analysis of blood concentration of methoxyflurane using 0.1 per cent methoxyflurane and 40 per cent oxygen. Br. J. Anaesth. 44: 1050 (1972).

9. MoIr, D.D. Anaesthesia for Caesarean section. An evaluation of method using low concentrations of halothane and 50 per cent oxygen. Br. J. Anaesth. 42: 136 (1970).

10. Rorke, M.J., DaveY, D.A., \& DU ToIT, H.J. Foetal oxygenation during Caesarean section. Anesthesia 23: 585 (1968).

11. MARX, G.F. \& MATEO, C.V. Effects of different oxygen concentrations during general anaesthesia for elective Caesarean section. Canad. Anaesth. Soc. J. 18: 586 (1971).

12. Baraka, A. Correlation between maternal and foetal $P_{\mathrm{O}_{2}}$ and $\mathrm{P}_{\mathrm{CO}_{2}}$ during Caesarean section. Br. J. Anaesth. 42: 434 (1970).

13. Severinghaus, J.W. Blood gas calculator. J. Appl. Physiol. 21: 1108 (1966).

14. Hellegers, A.E. \& Schruefer, J.J.A. Nomograms and empirical equations relating oxygen tension, percentage saturation, and $\mathrm{pH}$ maternal and fetal blood. Am. J. Obstet. Gynecol. 81: 337 (1961).

15. Palahniuk, R.J., Shnider, S.M., \& Eger, E.I. Pregnancy decreases the requirements for inhaled anesthetic agents. Anesthesiology 41: 82 (1974).

16. Palahniuk, R.J. \& Shnider, S.M. Matemal and fetal cardiovascular and acid-base changes during halothane and isoflurane anesthesia in the pregnant ewe. Anesthesiology 41: $462(1974)$. 